\title{
A de novo marker chromosome derived from $9 p$ in a patient with $9 p$ partial duplication syndrome and autism features: genotype-phenotype correlation
}

\author{
Khaled K Abu-Amero ${ }^{1 *}$, Ali M Hellani ${ }^{2}$, Mustafa A Salih ${ }^{3}$, Mohammad Z Seidahmed ${ }^{4}$, Tageldin S Elmalik, \\ Ghassan Zidan ${ }^{6}$, Thomas M Bosley ${ }^{1,7}$
}

\begin{abstract}
Background: Previous studies focusing on candidate genes and chromosomal regions identified several copy number variations (CNVs) associated with increased risk of autism or autism spectrum disorders (ASD).

Case Presentation: We describe a 17-year-old girl with autism, severe mental retardation, epilepsy, and partial 9p duplication syndrome features in whom GTG-banded chromosome analysis revealed a female karyotype with a marker chromosome in $69 \%$ of analyzed metaphases. Array CGH analysis showed that the marker chromosome originated from 9p24.3 to 9p13.1 with a gain of $38.9 \mathrm{Mb}$. This mosaic 9p duplication was detected only in the proband and not in the parents, her four unaffected siblings, or 258 ethnic controls. Apart from the marker chromosome, no other copy number variations (CNVs) were detected in the patient or her family. Detailed analysis of the duplicated region revealed: i) an area extending from 9p22.3 to 9p22.2 that was previously identified as a critical region for the 9p duplication syndrome; ii) a region extending from 9p22.1 to 9p13.1 that was previously reported to be duplicated in a normal individual; and iii) a potential ASD locus extending from 9p24.3 to 9p23. The ASD candidate locus contained 34 genes that may contribute to the autistic features in this patient.
\end{abstract}

Conclusion: We identified a potential ASD locus (9p24.3 to 9p23) that may encompass gene(s) contributing to autism or ASD.

\section{Background}

Autism spectrum disorders (ASD), including autism, are neuro-developmental disorders characterized by impairment in social and communication skills together with stereotyped and repetitive behavior and/or a restricted range of interests. Current prevalence estimates in the United States are $0.1-0.2 \%$ of live births for autism and $0.6 \%$ for ASD [1]. The exact prevalence of ASD in Saudi Arabia is still undetermined, but one rough estimate is 18 per 10,000 , slightly higher than 13 per 10,000 reported in developed countries [2]. Reasons for a possibly higher prevalence of ASD in Saudi Arabia are not clear but could relate in part to differences in diagnostic

\footnotetext{
* Correspondence: abuamero@gmail.com

'the Ophthalmic Genetics Laboratory, Department of Ophthalmology,

College of Medicine, King Saud University, Riyadh, Saudi Arabia

Full list of author information is available at the end of the article
}

practice, higher consanguinity rates, a founder effect, or unidentified environmental risk factors.

Previous studies focusing on candidate genes and chromosomal regions identified several copy number variations (CNVs) associated with increased risk of ASD [3-9]. Chromosomal regions implicated by these studies include 1q, 1p, 5q, 7q, 15q, 16p, 17p, 20p, 3p, 10q, 15q, $20 p, 22 q$ and $X q$ with patients exhibiting variable expressivity and associated phenotypes such as schizophrenia, mental retardation, developmental delay, and epilepsy [10]. The Autism Chromosome Rearrangement Database (http://projects.tcag.ca/autism) currently lists 15 reports of autistic patients with chromosomal anomalies involving 9p. Eleven of these cases involved CNVs of $9 p$ together with other chromosomes, while four cases involved an isolated $9 \mathrm{p}$ deletion or inversion. We describe a 17 -year-old girl with autism, mental 
retardation, and epilepsy with features of the 9p duplication syndrome who has a mosaic marker chromosome derived from 9p24.3 to 9p13.1.

\section{Case Presentation}

The proband (II-3, Figure 1A) was first examined at age 15 months because of seizures and developmental delay and has been followed since then by MAS and MZS. She has been institutionalized for most of her life. Her parents were unrelated Saudi Arabs, and she had four unaffected siblings, although the family history included epilepsy and cerebral palsy in maternal cousins. Pregnancy was unremarkable, delivery was normal at term, and she had no neonatal problems. This study was performed in accordance with the regulations of the King Saud University College of Medicine Ethics Committee (approval \# E-09-010), and the proband's legal guardian signed informed consent. The study adhered to the tenets of the Declaration of Helsinki.

At the age of 10 months, she developed flexion myoclonic jerks with hypsarrhythmia on EEG typical of infantile spasms, and she was treated with a course of prednisone $(2 \mathrm{mg} / \mathrm{kg}$ ) and clonazepam. A repeat EEG was moderately abnormal with multifocal epileptic discharges consistent with secondary symptomatic epilepsy, and she was started on the anticonvulsants vigabatrin and clonazepam and on risperidone for autistic behavior. Vigabatrin was successfully withdrawn and replaced by lamotrigine with no seizures after the age of $3 \frac{1}{2}$ years. She had delayed motor and cognitive functions, sitting at 13 months and walking at 2 years. She never developed speech, and she was diagnosed as severely mentally retarded with autistic features at age 6 years with a Vineland social maturity scale score of 31 . She was unable to feed herself and was incontinent of both stool and urine.

Laboratory investigation revealed normal hematologic indices, liver function, and electrolytes. Tandem mass spectrometry (TMS) for metabolic disorders was unremarkable. MRI of the brain and brainstem auditory evoked responses were both normal.

On examination, she had growth retardation with reduced weight (28.3 kg; <2 SD below the mean), height $(137 \mathrm{~cm} ;<2 \mathrm{SD})$, and head circumference $(49 \mathrm{~cm} ;<3$ SD). She had subtle dysmorphic features consistent with a partial 9p duplication syndrome with deep set eyes, small upper lip, webbing of the neck (Figure 1B) and clinodactyly (Figure $1 \mathrm{C}$ ). X-rays of hands and wrists revealed normal bone age with osteoporosis and confirmed clinodactyly of the fifth finger (Figure 1D). She

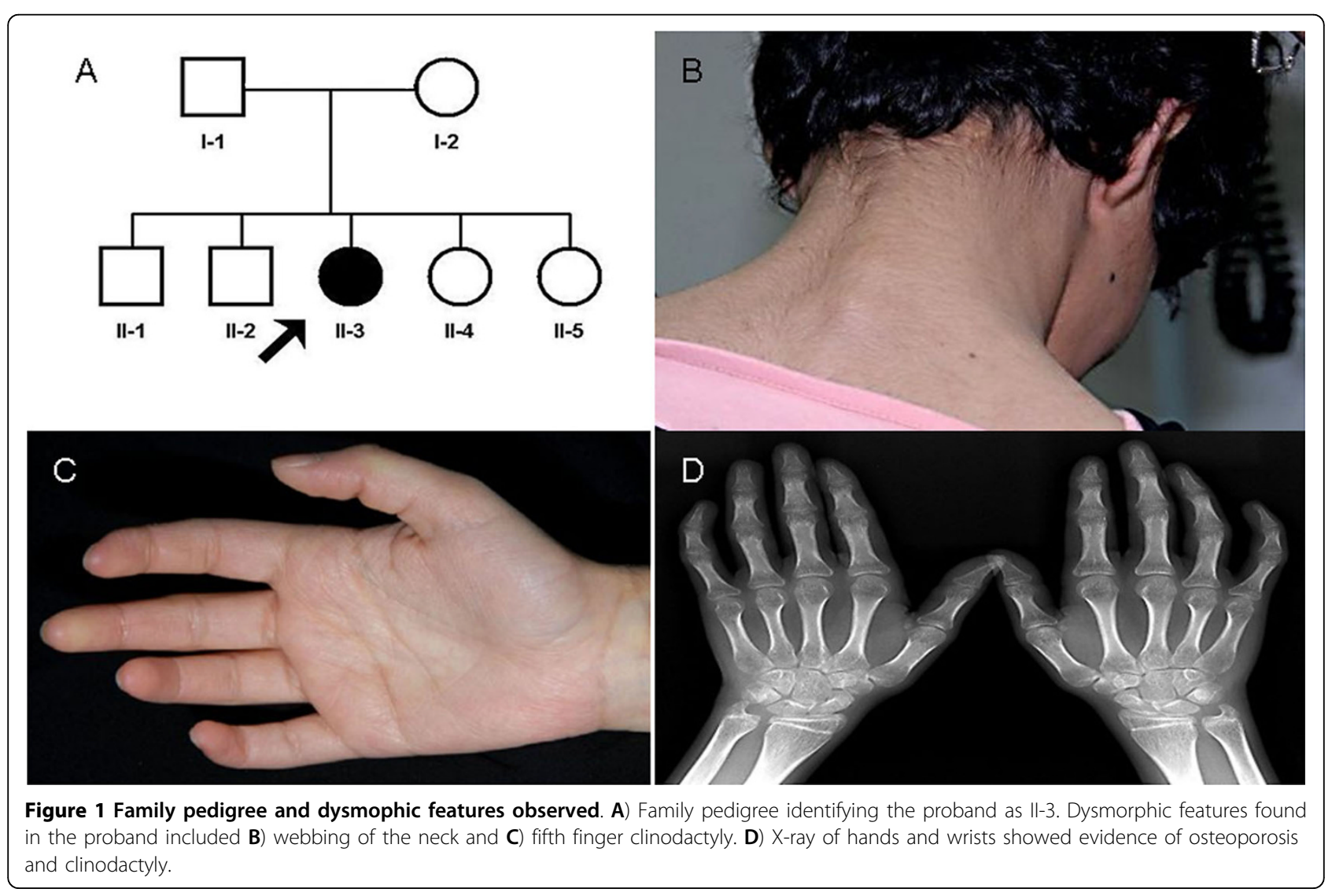


had no skin hypopigmentation or other stigmata of neurocutaneous disorders, but the dorsum of the left hand and the bridge of her nose were hyperpigmented because of self injury.

On neurologic examination, she was awake and alert but unable to follow commands or speak other than some echolalia and repetitive non-specific sounds. She moved all four extremities with normal tone; reflexes were brisk, but toes were down going. Ophthalmologic exam and ocular motility were grossly normal, but she did not make eye contact. She responded appropriately to visual threat and loud sounds. She was generally quiet and motionless, typically leaning to one side in an awkward posture, making stereotyped movements of her hands and trunk, and frequently hitting her nose with her hand and grinding her teeth. Social interaction was minimal with no smile, response to commands, or copying of examiner's movements. Applying DSM4-R criteria and PDD assessment scale/screening questionnaire, a psychiatric assessment yielded the diagnoses of (Axis I) pervasive developmental disorder (autistic type) and (Axis II) severe mental retardation.

Conventional cytogenetic analysis on GTG-banded chromosomes was performed according to the standard technique on cultured lymphocytes from the father (I-1), the mother (I-2), the proband (II-3), and her unaffected brother (II-1) after obtaining informed consent. GTGbanded chromosomes analysis was not carried out on individuals II-2, II-4 and II-5 (see Pedigree Figure 1A).

Agilent human $\mathrm{CGH}$ microarrays (Agilent Technologies, Santa Clara, CA, USA) were employed on individuals I-1, I-2, II-1, II-2, II-3, II-4, and II-5 using chips containing unique oligonucleotides for 244,000 probes $(244 \mathrm{~K})$ with average probe spacing across the human genome of $6.4 \mathrm{~Kb}$. Labeling reactions were performed with $1 \mu \mathrm{g}$ genomic DNA with Agilent Genomic DNA Labeling Kit PLUS (Agilent Technologies) according to manufacturer's protocol, and the microarray chip was then scanned by the Agilent Microarray Scanner.

Data analysis was performed by Agilent Feature Extraction 9.1 and CGH Analytics 3.4. In brief, $\log 2$ expression ratios were computed and normalized for forward and reverse fluor (i.e. dye-swap) experiments using the CGH Analytics 3.4 software. Putative chromosome copy number changes were defined by intervals of three or more adjacent probes with $\log 2$ ratios suggestive of a deletion or duplication when compared with the $\log 2$ ratios of adjacent probes. The quality-weighted interval score algorithm (ADM2) was used to compute and assist in the identification of aberrations for a given sample. Controls were 258 normal individuals of similar ethnic background. Genetic databases employed included Genbank (http://www.ncbi.nlm.nih.gov/genbank/), GeneCards (http://www.genecards.org/), the
Autism Chromosome Rearrangement Database (http:// projects.tcag.ca/autism), OMIM (http://www.ncbi.nlm. nih.gov/sites/entrez?db=omim) and literature search on PubMed (http://www.ncbi.nlm.nih.gov/pubmed).

Conventional cytogenetic analysis on GTG-banded chromosomes revealed a female karyotype in the proband with a marker chromosome (Figure 2A) in 69\% of the analyzed metaphases after counting more than 150 metaphase spreads; thus, her karyotype was 47,XX,+mar [69]/46,XX[31]. The marker chromosome was relatively small and was found in the proband but not in her parents or unaffected sibling (II-1), all of whom had a normal karyotype. No other chromosomal abnormalities were detected in the patient, or her parents, or her tested unaffected sibling (II-1).

Oligonucleotide whole genome array CGH analysis showed that the isolated marker chromosome originated from $9 \mathrm{p}$. The duplicated area started from the region surrounding the CBWD1 locus and included 9p24.3 to 9p13.1 (from 153131 bp to 39131894 bp on chromosome 9) with a size of $38.9 \mathrm{Mb}$ (Figure $2 \mathrm{~B}$ ). This gain of chromosome $9 \mathrm{p}$ was detected only in the proband. Her parents, unaffected siblings (II-1, II-2, II-4 and II-5), and 258 ethnically matched controls all had normal array $\mathrm{CGH}$ results (Figure 2C). No other chromosomal abnormality was detected in any individual examined by array $\mathrm{CGH}$.

The NCBI Map Viewer revealed that the duplicated area encompassed 381 genes (Additional file 1: Table S1). Analysis of the duplicated area identified: i) an area extending from 9p22.3 to 9p22.2 previously identified as critical for the $9 p$ duplication syndrome [11]; ii) a region extending from 9p22.1 to 9p13.1 previously reported to be duplicated in a girl with minimal physical findings and normal IQ [11] and iii) a potential ASD locus extending from 9p24.3 to 9p23 (Figure 3). This potential ASD locus is contained within the larger area identified by Szatmari and colleagues (9p24.3 to 9p13.2) in their study of 33 CNV gains in patients with autism [5].

The first patient with trisomy $9 \mathrm{p}$ was described by Rethore et al. in 1970 [12], and more than 150 patients with partial or complete $9 \mathrm{p}$ trisomy have been reported since then [13]. In most patients, the 9p trisomic segment was derived from a parent carrying a reciprocal balanced translocation and was accompanied by a concurrent deletion of another chromosome. Isolated de novo duplications of $9 \mathrm{p}$ without a concurrent deletion are infrequent, with 15 patients reported to date [11,14-26]. Typical characteristics include growth and mental retardation, microbrachycephaly, deep and wide-set eyes with downslanting palpebral fissures, prominent nasal root with a bulbous nasal tip, down-turned corners of the mouth, low-set ears, short fingers and toes with hypoplastic nails, and delayed bone age. Clinodactyly has also been 


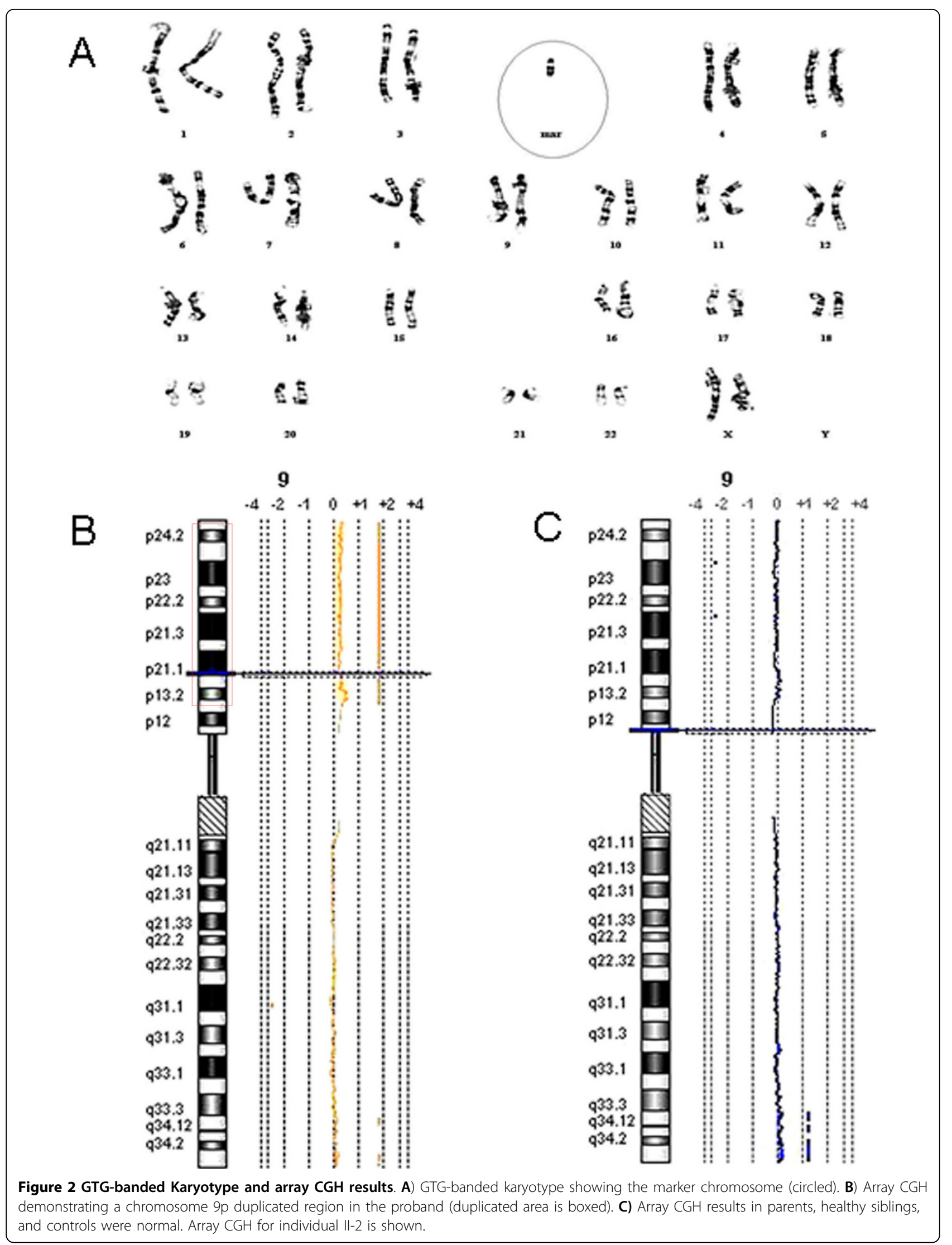




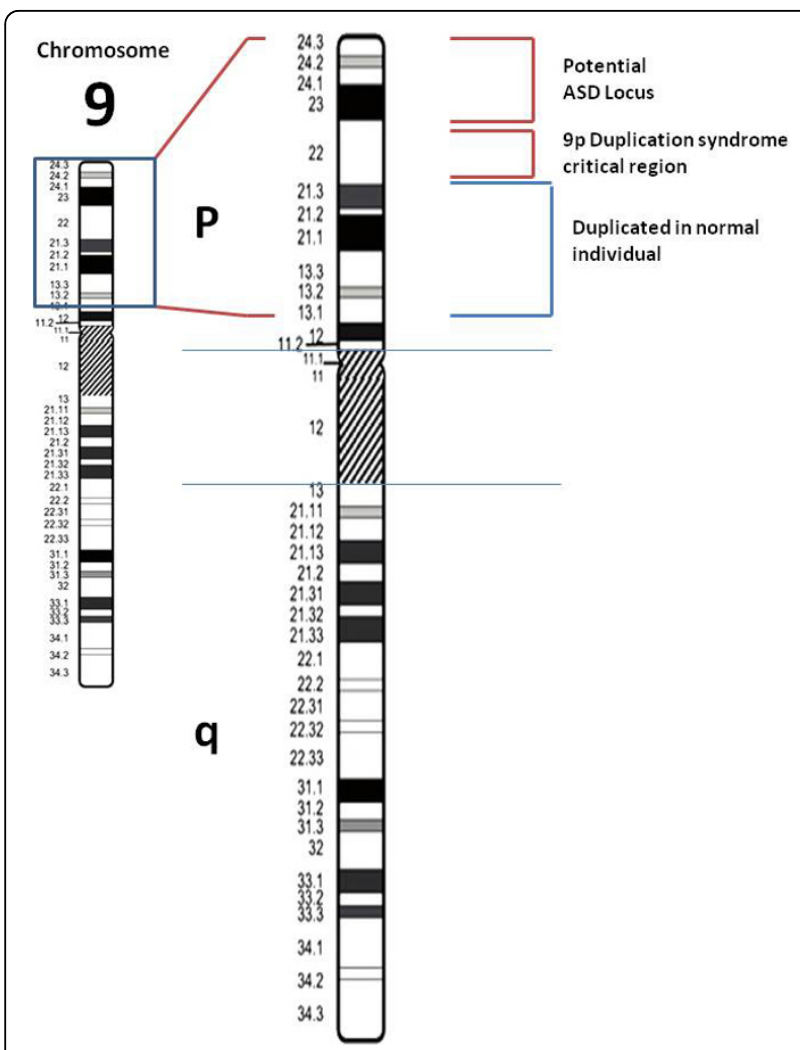

Figure 3 Ideogram showing the duplicated area. Chromosome 9 ideogram illustrating (to left, boxed) the overall duplicated area and (to right, labeled) the duplicated area in a normal individual, the $9 p$ duplication syndrome critical region, and the potential ASD locus.

reported in a patient with trisomy $9 \mathrm{p}$ and insertion on chromosome 12 [27]. Our patient had only partial 9p duplication features despite encompassing the entire $9 \mathrm{p}$ duplication critical region (D9S162-D9S267; 9p22.3 to 9 p22.2) in the duplication, and this may be because of the mosaic nature of the duplication.

One landmark study [28] provided evidence that chromosomal mosaicism plays an important role in the generation of meiotic aneuploidy, which in turn is recognized as a leading cause of human prenatal death, congenital malformations, and learning disabilities [29]. The largest study to date on mosaicism in autistic boys found mosaic aneuploidy in 19 of 116 children (16\%) with idiopathic autism [30]. The degree of mosaicism in our patient (69\%) may imply that gene dosage of $9 p$ is a factor contributing to autistic features; however, this remains unproven because other tissues, including brain, were not available.

We describe a 17-year-old Saudi girl with autism associated with mental retardation and seizures despite a non-focal neurologic examination and unremarkable neuroimaging [31]. Autism has not been associated previously with an isolated $9 p$ duplication [13], but this patient had a large, isolated, mosaic $9 \mathrm{p} 24.3$ to $9 \mathrm{p} 13.1$ duplication that is likely symptomatic given that the duplication was de novo, that it was not a polymorphic variant, that it segregated with autism in this family, and that some genes in the duplicated region have been linked previously to autistic features.

She had a potential ASD locus extending from 9p24.3 to 9 p23 (Figure 3) which, after removing hypothetical genes, encompassed 34 genes (Additional file 2: Table S2). The role of 16 of these genes in autism could not be assessed because they have unknown function using available databases and literature (see Methods). Of the 18 genes with known function, five (FOXD4L4, FOXD44L2, FOXD4, FOXD4L1 and FOXD2, all in the forkhead box gene family) are involved in transcription regulation. The very low density lipoprotein receptor gene $(V L D L R)$ belongs to a well-known family of similar genes that have the ability to transduce a diversity of extracellular signals across neuronal membranes in the adult central nervous system. Their role in modulating synaptic plasticity and their necessity in hippocampusspecific learning and memory are well documented [32]. Szatmari et al [5] and others [33-36] suggested that the genes DOCK8, DMRT1, DMRT3, and DMRT2 from this area of $9 \mathrm{p}$ may contribute to the autistic spectrum disorder phenotype [35]. The remaining eight genes in this locus (KANK1, EIF1, LOC642350, BHLHB3, SMARCA2, KCNV2, GPS2 and ATP5H) are involved in biological processes such as regulation of actin polymerization, nucleic acid binding, nucleotide and chromatin organization, mediating voltage-dependent potassium ion permeability, intracellular signaling, and ATP synthesis. No conclusion could be reached at this time about whether they may be involved in autism or ASD.

\section{Conclusion}

To our knowledge, this is the first report of an autistic patient with an isolated mosaic de novo 9p duplication. Analysis of the duplicated area identified a potential ASD locus 9p24.3 to 9p23, implying that screening this area for copy number variations by array CGH may help identify specific gene(s) contributing to autism or ASD.

\section{Additional material}

Additional file 1: Supplementary Table S1. Genes encompassed in the duplicated area.

Additional file 2: Supplementary Table S2. Potentially important genes in the duplicated area.

\section{Abbreviations}

Array CGH: Array comparative genomic hybridization; ASD: Autism spectrum disorders; CNVs: Copy number variations; DSM: Diagnostic and statistical 
manual of mental disorders; EEG: Electroencephalogram; mar: marker; MRI: Magnetic resonance imaging; PCR: Polymerase chain reaction; PDD: Pervasive developmental disorders; SD: Standard deviation; TMS: Tandem mass spectrometry

\section{Acknowledgements}

This work was supported by the Research Center of College of Medicine, King Saud University, Riyadh, Saudi Arabia. KAA and TMB were supported in part by the Glaucoma Research Chair of the Department of Ophthalmology, College of Medicine, King Saud University. Written consent was obtained from the patient or their relative for publication of this study.

\section{Author details}

'the Ophthalmic Genetics Laboratory, Department of Ophthalmology, College of Medicine, King Saud University, Riyadh, Saudi Arabia. ${ }^{2}$ the PGD Laboratory, Saad Specialist Hospital, Al-Khobar, Saudi Arabia. ${ }^{3}$ the Department of Pediatrics (Division of Pediatric Neurology), College of Medicine, King Saud University, Riyadh, Saudi Arabia. ${ }^{4}$ Department of Pediatrics, Security Forces Hospital, Riyadh, Saudi Arabia. ${ }^{5}$ Psychiatry Department, Security Forces Hospital, Riyadh, Saudi Arabia. ${ }^{6}$ Department of Pathology (Cytogenetics Laboratory), King Khalid University Hospital, Riyadh, Saudi Arabia. ${ }^{7}$ the Division of Neurology, Cooper University Hospital, Camden, NJ, USA.

\section{Authors' contributions}

KKA was in charge of study design, analysis of genetic data, and writing the genetic part of the manuscript. AH carried out array CGH studies. MAS, MZS, TSE and TMB were all essential in clinical evaluation of the patient and compiling the clinical data in the manuscript. GZ carried out the karyotyping. TMB was in charge of the overall project design, assessing clinical and genetic data, and writing the manuscript. All authors read and approved the final manuscript.

\section{Competing interests}

The authors declare that they have no competing interests.

Received: 22 April 2010 Accepted: 21 September 2010 Published: 21 September 2010

\section{References}

1. Newschaffer CJ, Croen LA, Daniels J, Giarelli E, Grether JK, Levy SE, Mandell DS, Miller LA, Pinto-Martin J, Reaven J, et al: The epidemiology of autism spectrum disorders. Annu Rev Public Health 2007, 28:235-258.

2. Al-Salehi SM, Al-Hifthy EH, Ghaziuddin M: Autism in Saudi Arabia: presentation, clinical correlates and comorbidity. Transcult Psychiatry 2009, 46(2):340-347.

3. Vorstman JA, Staal WG, van Daalen E, van Engeland H, Hochstenbach PF, Franke L: Identification of novel autism candidate regions through analysis of reported cytogenetic abnormalities associated with autism. Mol Psychiatry 2006, 11(1):18-28, 1.

4. Sebat J, Lakshmi B, Malhotra D, Troge J, Lese-Martin C, Walsh T, Yamrom B, Yoon S, Krasnitz A, Kendall J, et al: Strong association of de novo copy number mutations with autism. Science 2007, 316(5823):445-449.

5. Szatmari P, Paterson AD, Zwaigenbaum L, Roberts W, Brian J, Liu XQ, Vincent JB, Skaug JL, Thompson AP, Senman L, et al: Mapping autism risk loci using genetic linkage and chromosomal rearrangements. Nat Genet 2007, 39(3):319-328.

6. Marshall CR, Noor A, Vincent JB, Lionel AC, Feuk L, Skaug J, Shago M, Moessner $R$, Pinto $D$, Ren $Y$, et al: Structural variation of chromosomes in autism spectrum disorder. Am J Hum Genet 2008, 82(2):477-488.

7. Weiss $L A$, Shen $Y$, Korn JM, Arking DE, Miller DT, Fossdal R, Saemundsen E, Stefansson H, Ferreira MA, Green T, et al: Association between microdeletion and microduplication at 16p11.2 and autism. N Engl J Med 2008, 358(7):667-675.

8. Glessner JT, Wang K, Cai G, Korvatska O, Kim CE, Wood S, Zhang H, Estes A, Brune CW, Bradfield JP, et al: Autism genome-wide copy number variation reveals ubiquitin and neuronal genes. Nature 2009, 459(7246):569-573.

9. Klauck SM: Genetics of autism spectrum disorder. Eur J Hum Genet 2006, 14(6):714-720.
10. Craddock N, O'Donovan MC, Owen MJ: Psychosis genetics: modeling the relationship between schizophrenia, bipolar disorder, and mixed (or "schizoaffective") psychoses. Schizophr Bull 2009, 35(3):482-490.

11. Bonaglia MC, Giorda R, Carrozzo R, Roncoroni ME, Grasso R, Borgatti R, Zuffardi O: 20-Mb duplication of chromosome $9 p$ in a girl with minimal physical findings and normal IQ: narrowing of the $9 \mathrm{p}$ duplication critical region to $6 \mathrm{Mb}$. Am J Med Genet 2002, 112(2):154-159.

12. Rethore MO, Larget-Piet L, Abonyi D, Boeswillwald M, Berger R, Carpentier S, Cruveiller J, Dutrillau B, Lafourcade J, Penneau M, et al: [4 cases of trisomy for the short arm of chromosome 9. Individualization of a new morbid entity]. Ann Genet 1970, 13(4):217-232.

13. Zou YS, Huang XL, Ito M, Newton S, Milunsky JM: Further delineation of the critical region for the 9p-duplication syndrome. Am J Med Genet A 2009, 149A(2):272-276.

14. Chiyo H, Furuyama J, Suehara N, Obashi Y, Kikkawa H: Possible intrachromosomal duplication in a case of trisomy 9p. Hum Genet 1976 34(2):217-221.

15. Baccichetti C, Lenzini E, Forabosco A, Baroncini A, Dordo B, Mengarda G: [The syndrome of trisomy $9 p$ and presentation of 2 new cases]. Pathologica 1979, 71(1013):347-348

16. Fryns JP, Casaer $P$, Van den Berghe $H$ : Partial duplication of the short arm of chromosome 9 ( $p 13$ leads to p22) in a child with typical 9p trisomy phenotype. Hum Genet 1979, 46(2):231-235.

17. Zadeh TM, Funderburk SJ, Carrel R, Dumars KW: $9 p$ duplication confirmed by gene dosage effect: report of two patients. Ann Genet 1981, 24(4):242-244.

18. Cuoco C, Gimelli G, Pasquali F, Poloni L, Zuffardi O, Alicata P, Battaglino G, Bernardi $F$, Cerone $R$, Cotellessa $M$, et al: Duplication of the short arm of chromosome 9. Analysis of five cases. Hum Genet 1982, 61(1):3-7.

19. Coco R, Penchaszadeh VB: Cytogenetic findings in 200 children with mental retardation and multiple congenital anomalies of unknown cause. Am J Med Genet 1982, 12(2):155-173.

20. Motegi T, Watanabe K, Nakamura N, Hasegawa T, Yanagawa Y: De novo tandem duplication 9p (p12_- p24) with normal GALT activity in red cells. J Med Genet 1985, 22(1):64-66.

21. Mattina T, Sorge G, Milone G, Garozzo R, Conti L: Duplication 9p due to unequal sister chromatid exchange. J Med Genet 1987, 24(5):303-305.

22. Fujimoto A, Lin MS, Schwartz S: Direct duplication of $9 p 22->p 24$ in a child with duplication 9p syndrome. Am J Med Genet 1998, 77(4):268-271.

23. Stumm M, Musebeck J, Tonnies H, Volleth M, Lemke J, Chudoba I, Wieacker P: Partial trisomy 9p12p21.3 with a normal phenotype. J Med Genet 2002, 39(2):141-144.

24. Krepischi-Santos AC, Vianna-Morgante AM: Disclosing the mechanisms of origin of de novo short-arm duplications of chromosome 9. Am J Med Genet A 2003, 117A(1):41-46.

25. Temtamy SA, Kamel AK, Ismail S, Helmy NA, Aglan MS, El Gammal M, El Ruby M, Mohamed AM: Phenotypic and cytogenetic spectrum of $9 p$ trisomy. Genet Couns 2007, 18(1):29-48.

26. Roohi J, Tegay DH, Pomeroy JC, Burkett S, Stone G, Stanyon R, Hatchwell E: A de novo apparently balanced translocation $[46, X Y, t(2 ; 9)(p 13 ; p 24)]$ interrupting RAB11FIP5 identifies a potential candidate gene for autism spectrum disorder. Am J Med Genet B Neuropsychiatr Genet 2008, 147B(4):411-417.

27. de Pater JM, Ippel PF, van Dam WM, Loneus WH, Engelen JJ: Characterization of partial trisomy $9 p$ due to insertional translocation by chromosomal (micro)FISH. Clin Genet 2002, 62(6):482-487.

28. Hulten MA, Patel SD, Tankimanova M, Westgren M, Papadogiannakis N, Jonsson AM, Iwarsson E: On the origin of trisomy 21 Down syndrome. Mol Cytogenet 2008, 1:21.

29. Iourov IY, Vorsanova SG, Yurov YB: Chromosomal mosaicism goes global. Mol Cytogenet 2008, 1:26.

30. Yurov YB, Vorsanova SG, lourov IY, Demidova IA, Beresheva AK, Kravetz VS, Monakhov W, Kolotii AD, Voinova-Ulas WY, Gorbachevskaya NL: Unexplained autism is frequently associated with low-level mosaic aneuploidy. J Med Genet 2007, 44(8):521-525.

31. Youroukos S: Autism and Epilepsy. ENCEPHALOS Archives of Neurology and Phychiatry 2007, 44(2):200-203.

32. Qiu S, Korwek KM, Weeber EJ: A fresh look at an ancient receptor family: emerging roles for low density lipoprotein receptors in synaptic plasticity and memory formation. Neurobiol Learn Mem 2006, 85(1):16-29. 
33. Ottolenghi C, Veitia R, Barbieri M, Fellous M, McElreavey $\mathrm{K}$ : The human doublesex-related gene, DMRT2, is homologous to a gene involved in somitogenesis and encodes a potential bicistronic transcript. Genomics 2000, 64(2):179-186.

34. Ottolenghi C, Veitia R, Quintana-Murci L, Torchard D, Scapoli L, SouleyreauTherville N, Beckmann J, Fellous M, McElreavey K: The region on $9 p$ associated with $46, X Y$ sex reversal contains several transcripts expressed in the urogenital system and a novel doublesex-related domain. Genomics 2000, 64(2):170-178.

35. Vinci G, Chantot-Bastaraud S, El Houate B, Lortat-Jacob S, Brauner R, McElreavey K: Association of deletion 9p, 46,XY gonadal dysgenesis and autistic spectrum disorder. Mol Hum Reprod 2007, 13(9):685-689.

36. Veitia RA, Nunes M, Quintana-Murci L, Rappaport R, Thibaud E, Jaubert F, Fellous M, McElreavey K, Goncalves J, Silva M, et al: Swyer syndrome and $46, X Y$ partial gonadal dysgenesis associated with $9 p$ deletions in the absence of monosomy-9p syndrome. Am J Hum Genet 1998, 63(3):901-905.

\section{Pre-publication history}

The pre-publication history for this paper can be accessed here: http://www.biomedcentral.com/1471-2350/11/135/prepub

doi:10.1186/1471-2350-11-135

Cite this article as: Abu-Amero et al:: A de novo marker chromosome derived from $9 p$ in a patient with $9 p$ partial duplication syndrome and autism features: genotype-phenotype correlation. BMC Medical Genetics 2010 11:135.

\section{Submit your next manuscript to BioMed Central and take full advantage of:}

- Convenient online submission

- Thorough peer review

- No space constraints or color figure charges

- Immediate publication on acceptance

- Inclusion in PubMed, CAS, Scopus and Google Scholar

- Research which is freely available for redistribution

Submit your manuscript at www.biomedcentral.com/submit 